\title{
Licensed Practical Nurses becoming Registered Nurses: Conflicts and responses that can help
}

\author{
Kathryn Gordon ${ }^{1}$, Sherri Melrose ${ }^{2}$, Katherine J. Janzen ${ }^{3}$, J ean Miller ${ }^{2}$ \\ 1. Acute Care Addictions and Mental Health Services at Foothills Medical Centre, Calgary, Alberta, Canada. 2. Centre for \\ Nursing and Health Studies, Athabasca University, Athabasca, Alberta, Canada. 3. School of Nursing, Faculty of Health and \\ Community Studies, Mount Royal University, Calgary, Alberta, Canada.
}

Correspondence: Sherri Melrose. Address: Centre for Nursing and Health Studies, Athabasca University, 1 University Drive, Athabasca, Alberta, Canada. Email: sherrim@athabascau.ca

Received: June 23, 2013

Accepted: August 6, 2013

Online Published: August 8, 2013

DOI : $10.5430 / c n s . v 1 n 4 p 1$

URL: http://dx.doi.org/10.5430/cns.v1n4p1

\begin{abstract}
This article describes findings from a qualitative research project designed to understand the professional socialization experiences of Licensed Practical Nurses attending university to transition to the role of Registered Nurse. Findings revealed that this group of nursing students believed (Licensed Practical Nurse) LPN's were not respected, that their nursing knowledge as LPN's was not acknowledged and that it was challenging for them to feel a sense of belonging with the RN community. These insights have implications for practicing (Registered Nurse) RN's as student nurse groups are now including more Licensed Practical Nurses. Responding with reflection, communication and collegiality can offer important help to LPN to RN students.
\end{abstract}

\section{Key words}

(Licensed Practical Nurse) LPN to (Registered Nurse) RN transition, Nurse conflict, Responses to nurse conflict

\section{I ntroduction}

The transition from LPN to RN can be a difficult process. When Registered Nurse students are also practising Licensed Practical Nurses, nursing teams may not know how to best support and include these unique learners. All too often, LPN to RN students' feelings of inner conflict and ambivalence are overlooked during their clinical learning experiences. In our research exploring the professional socialization experiences of LPNs as they transitioned into the role of Registered Nurse, we conducted four focus groups with nurses advancing their nursing role. During discussions with these LPN colleagues currently in the role of student RNs, we learned that this group of nursing students believed LPNs were not respected, that their nursing knowledge as LPNs was not acknowledged, and that it was challenging for them to feel a sense of belonging with the RN community. Our findings have implications for practicing RNs, particularly preceptors, as student nurse groups are now including more LPNs. In this article, we discuss conflicts that can emerge as LPNs continue their education in nursing. Responding with reflection, communication, and collegiality will not only help support this group of learners, it will strengthen teamwork among all nurses. 


\subsection{Background and significance}

The experience of socializing into a new and more complex professional nursing role is seldom straightforward. Traditionally, LPN to RN bridging programs were not widely available. However, today a variety of opportunities exist where LPNs can advance their nursing education. And yet, little has been written about the professional socialization experiences of this new group of learners.

Our research project was framed from a constructivist conceptual framework. Constructivist epistemology suggests that individuals approach learning by actively collaborating and engaging with others in their environment to build on what they already know ${ }^{[1-3]}$. In clinical learning environments, collaboration and engagement with practicing nurses is particularly important to student nurses as they construct knowledge and seek to make sense of the world in their chosen profession. As practicing RNs interact with LPN to RN students to help them build on their existing knowledge, an understanding of what the concepts of both conflict and collegiality can look like through the students' eyes offers valuable guidance.

Conflict. Conflict is not unexpected when LPNs transition to the more complex role of RN ${ }^{[4-6]}$. The RN role involves more independence and accountability for client outcomes. As Kearney-Nunnery explained, LPNs collect client data and decide who needs to be informed while RN's synthesize client data and make independent decisions ${ }^{[5]}$. As LPN to RN students tentatively move away from a role where they were taught to inform others rather than make independent decisions, the idea that conflict could emerge for them becomes plausible.

LPN to RN students can feel a sense of loss as they move away from their familiar bedside nursing role ${ }^{[7]}$. Developing the independence needed to function as an RN is particularly difficult ${ }^{[8]}$. This "internal strain creates a state of ambivalence, conflicting internal dialogue or lack of resolution in one's thinking and feeling," known as intrapersonal conflict ${ }^{[9]}$. If left unresolved, interpersonal conflict (between members of a team) may result ${ }^{[10]}$. In turn, nurse communication and collegiality may be threatened, issues known to negatively impact patient care, teamwork, nurse satisfaction, and retention ${ }^{[11-14]}$. While conflict is an expected element in any transition ${ }^{[15-17]}$, the way we respond to colleagues experiencing conflict can help make the experience a more positive one.

Collegiality. Nursing literature increasingly recognizes the impact of nurse group cohesion/collegiality as important to nurse job satisfaction, retention, and quality of patient outcomes. A connection between quality of work life, role identity, and a sense of belonging has been acknowledged ${ }^{[18]}$. Higher levels of job satisfaction have been associated with teamwork ${ }^{[19]}$. Nurses' thoughts, behaviours, and attitudes are also considered central to effective teamwork; these skills can be learned and developed ${ }^{[20]}$. Optimizing communication between nurses has been acknowledged as necessary for patient safety ${ }^{[21]}$. However, collegiality may not always exist between LPNs and RNs. Although LPNs invest considerable emotional labour into their interactions with RNs, this investment often goes unrecognized ${ }^{[22]}$.

Knowing that employment of RNs is expected to grow 26 percent from 2010 to $2020^{[23]}$ and that $13 \%$ of new nurses will consider leaving their jobs in their first year, ${ }^{[24]}$ it is critically important for practicing nurses to "extend a hand of welcome" to our experienced LPN colleagues. When LPNs advance their nursing education, they are not new nurses and they are expected to stay in nursing. A deeper understanding of LPN to RN students' experiences in both their LPN role and their student RN role offers important insight into creating inclusive nursing teams.

\subsection{Purpose}

The main purpose of the study was to describe LPN to RN student nurses' experiences with professional socialization as they learned a more complex nursing role. A secondary purpose of the research was to begin to understand how practicing nurses can best respond and support these students' learning. 


\section{Method}

This qualitative project, framed from a constructivist worldview, is part of an overarching program of research exploring the transitions LPNs experience when they advance their education to become RNs. Participants were 27 LPNs enrolled in a baccalaureate nursing program, who were currently attending a practicum on an acute hospital unit.

Participants. The participants' LPN to RN bridging program is unique in that LPNs are awarded approximately two years prior academic credit towards their four year program. In Canada, a baccalaureate nursing degree is required in order to write the RN qualifying exam. Historically, university programs have not offered LPNs credit for their previous nursing credential. The bridging program is also unique in that all courses except the clinical practicums are delivered online.

Students come from across Canada and the only time they met in person was during practicums. In most instances, students left their families and full time employment and had to find accommodation in a new city in order to complete their month long practicums. Thus, in order to access students when they were in groups, the research was conducted when they were attending practicums.

Recruiting was done by emailing a Letter of Invitation to four groups of students scheduled to attend practicums on acute medical surgical units. The Facilitators collected the names and arranged meetings at times when clinical shifts were over for the day. All recruitment and facilitation was implemented by researchers who were not known to participants and who had no teaching or evaluation responsibilities in their program. Interestingly, all the students who received the invitation participated. We reasoned that this was in part related to the fact that most were from out of town, that few other non-program opportunities were available and that the timing was convenient.

Participants were adult learners with diverse demographics. They included two males and twenty five females with ages ranging from early twenties through to late forties. Their practice areas included acute hospital units such as medicine and surgery, urban and rural community clinics and care homes for the aged. While some participants had practiced as LPNs for two years, others had practiced for over twenty years. Some had practiced on acute hospital units very similar to the practicum placements and others had no previous practice experience on acute hospital units. They brought a range of existing nursing knowledge to their learning and had varied learning needs.

Practicums. The two hospital units where the four groups of participants completed their practicums were located in different cities. As clinical placements for all RN students throughout the province were centrally coordinated, LPN to RN students were assigned to the same units as traditional RN students. Patients on these units were acutely ill, remained only for short periods and required a high level of nursing care. Nursing staff on the units included a mix of LPNs and RNs and informal student and instructor evaluations of these units as practicum placements were very positive.

Data Sources. Data sources were four face-to-face digitally recorded, transcribed focus group discussions. The focus groups were conducted in different cities with different participants over a period of two university terms.

A semi structured interview guide, framed around questions related to professional socialization was used. For example, participants were invited to discuss their perceptions of the concept of "professional socialization". They were encouraged to discuss the formal academic and clinical experiences that supported or distracted from their learning. And they were invited to discuss the informal experiences that supported or distracted from their learning. In all four groups, discussions became particularly animated during discussions of learning distractions.

At the beginning of each session, the facilitators identified group ground rules which included an expectation that all comments would remain confidential. They used pseudonyms when entering data, ensured consent forms were signed and emphasized that participants were free to discontinue their involvement at any time. 
Data Analysis. QSR International's NVIVO $10^{[25]}$ was implemented to organize thematic analysis of the focus group transcripts. Line by line coding was used to group participants' phrases and conversations (indicators) into meaningful qualitative units or categories of concepts ${ }^{[26]}$ In keeping with naturalistic inquiry, these categorizations in turn led to the development of overarching themes ${ }^{[2]}$. The transcripts were thoroughly read and re-read and the research team met regularly to discuss our interpretations and develop a systematic process of thematic analysis. Investigator triangulation and member checking with participants ensured trustworthiness and authenticity of the findings. Full ethical approval was granted by the university's Ethics Review Board.

In this article, we discuss three themes that begin to illustrate some of the conflicts that this group of learners expressed as they continued their education as nurses. First, this group of nursing students believed LPNs were not respected. Second, they felt that their nursing knowledge as LPNs was not acknowledged. Third, they expressed that it was challenging for them to feel a sense of belonging within the RN community.

\section{Results}

Theme 1: LPNs are not respected. Participants frequently commented on their belief that LPNs were not respected by other members of the healthcare team. In particular, they did not feel that the LPN role was as respected as the RN role. They mentioned that while people often don't know what LPNs do, the role of the RN is more familiar. One participant remarked that "people look at LPNs differently, kind of like a nursing attendant or something, because that's kind of what we've been historically." For some of our participants, their motivation to advance from the role of LPN to RN centered on a belief that the LPN role was less respected.

They talked about how they felt undervalued when they practiced as LPNs. The LPN to RN students spoke positively about many of their new experiences as student RNs as they were beginning to sense the additional collegiality and respect they would experience when they finished their program. They wondered why this same sense of cohesion and respect had not been possible in their LPN role. The following excerpt reflects this perceived interpersonal conflict among nurses and a desire for change.

I know the respect will be different [as an RN]. I find this kind of frustrating. I've taken this last year off to go to school full-time and complete my degree and [now] all the doctors and all my co-workers are like "Good for you!” They're so excited for me! But then it makes me sad that I'm giving up LPN. Yeah, like I'm getting all that extra respect, but why couldn’t I have had that before when I was doing my job so well?

Theme 2: LPN nursing knowledge is not acknowledged. Similarly, LPN to RN students felt that their LPN knowledge was not acknowledged by other members of the healthcare team. As one participant explained: "You get that stigma, people see you as somebody who is maybe not what an RN is, even though you're all members of the team."

Nurses in this study were largely female, over 30, culturally diverse, with considerable work experience. As mature learners, many were employed with family commitments and other responsibilities. They had established their identities as nurses before returning to the role of student. During the focus group discussions, they often mentioned how a seeming lack of consideration for their existing knowledge left them feeling hurt and longing for acknowledgement of the important contributions LPNs bring to the nursing profession.

When discussing how an instructor required a return demonstration of a skill she mastered as an LPN, one nurse commented:

It's almost like there's no recognition for what we've done in our careers and that is extremely frustrating because it's like none of that mattered. Do you know what I mean? Supposedly it's this LPN to RN [new knowledge] thing. But it's like [no one] really cares that you're an LPN. You're starting from scratch 
Further, when discussing her perceptions that RNs did not acknowledge LPNs as nurses who could think critically, one student stated: I've had a lot of RN's talk to me and say LPN's don't know how to think critically." Another participant also expressed: "Obviously I have some skills and some critical thinking ... enough to pass as someone who is knowledgeable in my job, in my profession. I'm sick of being undervalued [in the LPN role].”

Theme 3: Desire to belong. LPN to RN students expressed that it was challenging for them to feel a sense of belonging with the RN community as they tried to learn the RN role. In clinical practicums, when they were assigned tasks they had already mastered as LPNs or were partnered with practicing LPNs, they struggled to understand their future role. Practicing RNs were often unaccustomed to students who brought such a wealth of existing nursing knowledge to their learning experiences. This limited understanding was at times viewed as exclusionary. However inadvertent, by being excluded from learning opportunities only available to practicing RNs, they were not always able to fulfill their desire to belong. The following quote illustrates one student's need to belong to an RN community versus continuing to identify with her LPN peers.

I found it kind of ironic, though. It was weird. Like we didn't team up all the time with RNs. So you're trying to create this [new identity] and appreciate the difference between [LPNs and RNs]. But your buddy's an LPN and so you're trying to think, “Okay, am I thinking like an LPN or am I thinking like an RN?” And so that was a little difficult because then you still related on an LPN kind of level. So I found that a little difficult. Like it would have been more interesting if we could have maybe like sat with, like been with the charge nurse, like you know, because that's a role that you would do.

\section{Discussion and implications}

After listening carefully to the experiences of LPN colleagues as they shared their experiences transitioning to the RN role, our research team reflected on how nurses could best respond and help this group of nurse learners. A change in one's job is a well-known stressful life event ${ }^{[27]}$. Transitioning from one nursing role to another can evoke differing emotions and might precipitate intra- and potentially interpersonal conflict between nurse colleagues. LPN to RN learners seek help from workplace mentors to apply their learning ${ }^{[28]}$. And yet, when they feel other nurses do not respect the LPN role as much as the RN role, do not adequately acknowledge LPN knowledge, and they aren't exposed to RN experiences that help them become part of the RN community, seeking help becomes difficult.

Viewing the process of entering the RN community through the eyes of LPN to RN students, the conflict with both self and others can seem overwhelming. Practicing RNs, particularly preceptors, play a pivotal role in the professional socialization and successful transition of these experienced nurse learners. The following suggestions, grounded in the concepts of reflection, communication, and collegiality, are offered for responding and helping LPN colleagues as they adjust to their new roles.

\subsection{Reflection}

As practicing RNs we often encounter new and difficult situations which have the potential to precipitate both intra- and interpersonal conflict. Reflection offers us the opportunity to apply active, focused thought to an experience in order to gain insight into that experience, leading to new perspectives, learning, and a change in future action. Various models of reflection have been identified in the nursing literature. Johns' structured model of self-reflection ${ }^{[29]}$ is considered easy to use as it provides a series of steps that prompt consideration of an event. ${ }^{[29-31]}$ This model acknowledges the influence of past experience on the present and enables nurses to probe these experiences on a deeper level. Reflecting upon the following six questions could help practicing RNs consider ways to improve transition experiences, and their associated conflicts, giving rise to practice changes which enhance teamwork amongst all nurses: ${ }^{[29]}$

1) How does this situation relate to previous experiences? 
2) Could I handle this better in similar situations?

3) What would be the consequences of alternative actions for the patient, others, or myself?

4) How do I feel now about this experience?

5) Can I support myself and others better as a consequence?

6) Has this changed my ways of knowing?

\subsection{Communication}

Communication (verbal and nonverbal) is part of everything we do as nurses and it influences all we come into contact with. As the provision of safe, quality patient care is a common goal of both LPNs and RNs; our ability to effectively communicate with each other becomes increasingly important in today's complex and hectic healthcare environments.

Communication can be strengthened and potential misunderstandings can be reduced when nurses intentionally engage in positive interactions with colleagues (e.g. communicate openly and directly; validate their professional expertise and importance in patient care). These reflect the respect so essential to effective collaboration ${ }^{[32-35]}$. Whether their credential is LPN or RN, it is important for all nurses to discuss their common interests and clarify areas of positive interdependence (e.g. values, shared goals) ${ }^{[36-38]}$. Knowing that words can inadvertently be hurtful, nurses can make a point of rectifying language patterns which could exclude or demean ${ }^{[39]}$ any nurse group. Avoiding and not acknowledging that conflicts exist can keep nursing groups from communicating effectively ${ }^{[40]}$.

The simple process of listening to others' viewpoints can be the heart of effective communication. Sometimes no response is required, just a listening ear and a sense of support and understanding is all that's needed ${ }^{[41]}$. Once individuals genuinely feel they have been heard and their concerns acknowledged, it is possible to progress towards seeking further information and eventually arriving at a joint understanding of problems. Being willing to discuss ways of working together leads to the development of joint solutions ${ }^{[42]}$. As with any team, when LPNs and RNs engage in meaningful discussions about dealing with issues, the outcomes can lead to optimism, change, and growth in the nursing profession ${ }^{[42]}$.

\subsection{Collegiality}

Work environments which offer members a sense of acceptance and connectedness positively impact patient care and nurse retention rates ${ }^{[43-45]}$. Building communities which emphasize these elements can help promote a cooperative orientation which encourages constructive conflict management when issues do arise. Welcoming LPN to RN learners into the RN nursing community can begin by expressing a willingness and commitment to serving as an RN role model.

Acknowledging and respecting the differences that exist between nurse colleagues is important ${ }^{[46]}$. If LPNs are not usually included in team meetings, consider inviting them whenever possible. Regular meetings enhance communication amongst team members, help resolve interpersonal conflict and promote positive interpersonal relations ${ }^{[47]}$. When workshops on conflict management become available, LPNs and RN's attending together can shed light on LPN issues that RNs may not be aware of. Conflict management helps develop effective communication and coping skills ${ }^{[44]}$. Similarly, positive team building will evolve when conflict is managed effectively.

\section{Conclusion}

This article presented findings from a qualitative study that explored Licensed Practical Nurses' perceptions of becoming socialized into the role of Registered Nurse. Unlike other studies that focused on traditional student nurses, this project offers new information about a unique group of nurse learners. This research found that LPN to RN students believed that LPNs were not respected, that their nursing knowledge as LPNs was not acknowledged, and that it was challenging for them to feel a sense of belonging within the RN community. The limited sample is not intended to represent all LPN to RN 
students and further research is needed to extend our findings. We call on practicing RNs, particularly preceptors, to respond with reflection, communication, and collegiality to our LPN colleagues as they work through the intra- and interpersonal conflicts associated with transitioning to a new and more complex nursing role. We applaud their efforts and invite continued dialogue about ways to welcome and include LPNs on our teams and in our learning opportunities.

\section{Acknowledgement}

This study is funded as a part of a larger research study by the Social Sciences and Humanities Research Council of Canada.

\section{Declarations of interest}

The authors declared no conflict of interest.

\section{References}

[1] Melrose S. Constructivism: Building on what learners already know. In S. Melrose, C. Park, \& B. Perry (Eds.), Teaching health professionals online: Frameworks and strategies. Athabasca, AB, Canada: AU Press; 2013 (in press).

[2] Lincoln YS, Guba EG. Naturalistic inquiry. Newbury, CA: Sage Publications; 1985.

[3] Vygotsky LS. Mind and society: The development of higher psychological processes. Cambridge, MA: Harvard University Press; 1978.

[4] Claywell L. LPN to RN Transitions. 3rd ed. St. Louis, MI: Mosby; 2013.

[5] Kearney-Nunnery R. Making the transition from LPN to RN. Philadelphia, PA: Davis; 2010.

[6] Harrington N, Terry C. LPN to RN transitions: Achieving success in your new role. 4th ed. Philadelphia, PA: Lippincott Williams \& Wilkins; 2012.

[7] Melrose S, Gordon K. Online Post LPN to BN students' views of transitioning to a new nursing role. International Journal of Nursing Education Scholarship. 2008; 5(1):14. PMid:18384272 http://dx.doi.org/10.2202/1548-923X.1588

[8] Melrose S., Wishart P. Resisting, reaching out and re-imagining to independence: LPNs transitioning to BNs and beyond. International Journal of Nursing Education Scholarship. 2013; 10(1):1-7. PMid:23735437 http://dx.doi.org/10.1515/ijnes-2012-0033

[9] Wilmot W, Hocker J. Interpersonal conflict. 7th ed. New York, NY: McGraw-Hill; 2007: 9.

[10] Wilmot W, Hocker J. Interpersonal conflict. 8th ed. New York, NY: McGraw-Hill; 2010.

[11] Nazaam D. Nurses’ role in communication and patient safety. Journal of Nursing Care Quality. 2009;24(3):184-188. PMid:19525757 http://dx.doi.org/10.1097/01.NCQ.0000356905.87452.62

[12] Institute of Medicine. Keeping patients Safe: Transforming the work environment of nurses. Washington, DC: National Academies Press [Internet]. 2004 [cited 2013 Aug 8]. Available from: http://books.nap.edu/openbook.php?record_id=10851\&page=23

[13] MacPhee M, Wardrop A, Campbell C. Transforming workplace relationships through shared decision making. Journal of Nursing Management. 2010;18(8):1016-1026. PMid:21073573 http://dx.doi.org/10.1111/j.1365-2834.2010.01122.x

[14] Pellico L, Djukic M, Kovner C, Brewer C. Moving on, up, or out: Changing work needs of new RNs at different stages of their beginning nursing practice. Online Journal of Issues in Nursing [Internet]. 2010 [cited 2013 Aug 8]; 15(1). Available from http://www.medscape.com/viewarticle/712189

[15] Bridges W. Transitions: Making sense of life’s changes. Menlo Park, CA: Addison-Wesley; 1980.

[16] Bridges W. The way of transitions: Embracing life's most difficult moments. New York, NY: William Bridges and Associates, Perseus Books; 2001.

[17] Bridges W. Managing transitions: Making the most of change. 3rd ed. New York, NY: William Bridges and Associates, Perseus Books; 2009.

[18] Roy C. The Roy adaptation model. 3rd ed. Upper Saddle River, NJ: Pearson Education; 2009.

[19] Kalish B, Lee H, Rochman M. Nursing staff teamwork and job satisfaction. Journal of Nursing Management. 2010;18(3): 938-947. PMid:21073567 http://dx.doi.org/10.1111/j.1365-2834.2010.01153.x

[20] Kalish B, Lee H, Salas E. The development and testing of the nursing teamwork survey. Nursing Research. 2010;59(1): 42-50. PMid:20010044 http://dx.doi.org/10.1097/NNR.0b013e3181c3bd42

[21] Cunningham J, Leisch J. Nursing handoffs: A systematic review of the literature. American Journal of Nursing, 2010;110(4): 24-34. PMid:20335686 http://dx.doi.org/10.1097/01.NAJ.0000370154.79857.09 
[22] Huynh T, Alderson M. Nadon M, Kershaw-Rousseau S. Voices that care: Licensed Practical Nurses and the emotional labour underpinning their collaborative interactions with Registered Nurses. Nursing Research and Practice [Internet]. 2011 [cited 2013 Aug 8];Vol. 2011. Available from: http://www.hindawi.com/journals/nrp/2011/501790/

[23] Bureau of Labor Statistics US. Department of Labor. Occupational outlook handbook, 2012-13 Edition, Registered Nurses [Internet]. 2012 Mar 29 [cited 2013 Aug 8]. Available from http://www.bls.gov/ooh/healthcare/registered-nurses.htm

[24] Kovner C, Brewer C, Fairchild S, Poornima S, Kim H, Djukic M. Newly licensed RNs' characteristics, work attitudes and intentions to work: A better understanding of newly licensed RNs and their employment patterns is crucial to reducing turnover rates. American Journal of Nursing. 2007;107(9):58-70. PMid:17721152 http://dx.doi.org/10.1097/01.NAJ.0000287512.31006.66

[25] NVivo qualitative data analysis software; QSR International Pty Ltd. Version 10; 2013.

[26] Chenail R. Conducting qualitative data analysis: Reading line-byline, but analyzing by meaningful qualitative units. The Qualitative Report. 2012; 17(1); 266-269.

[27] Holmes TH, Rahe RH. The Social Readjustment Rating Scale. Journal of Psychosomatic Research. 1967;11:213-218. http://dx.doi.org/10.1016/0022-3999(67)90010-4

[28] Melrose S, Gordon K. Overcoming barriers to role transition during an online post LPN to BN program. Nurse Education in Practice. 2011; 11(1):31-35. PMid:20619741 http://dx.doi.org/10.1016/j.nepr.2010.06.002

[29] Johns C. Framing learning through reflection within Carper's fundamental ways of knowing in nursing. Journal of Advanced Nursing. 1995; 22(2):226-234. PMid:7593941 http://dx.doi.org/10.1046/j.1365-2648.1995.22020226.x

[30] Jasper M. Foundations in nursing and health care: Beginning reflective practice. Cheltenham, UK: Nelson Thornes; 1995.

[31] Duffy A. A concept analysis of reflective practice: Determining its value to nurses. British Journal of Nursing. 2007;16(22):1400-1407. PMid:18361389

[32] Almost J, Doran DM, McGillis Hall L, Spence Laschinger HK. Antecedents and consequences of intra-group conflict among nurses. Journal of Nursing Management. 2010; 18(8):981-992. PMid:21073570 http://dx.doi.org/10.1111/j.1365-2834.2010.01154.x

[33] Kupperschmidt B. Conflicts at work? Try carefronting. Journal of Christian Nursing. 2008; 15(1):10-19. http://dx.doi.org/10.1097/01.CNJ.0000305998.97252.fd

[34] Hahn J. Effectively manage a multigenerational staff. Nursing Management. 2009; 40(9):8-10. PMid:19734749 http://dx.doi.org/10.1097/01.NUMA.0000360765.52105.ed

[35] Dieleman SL, Farris KB, Feeny D, Johnson JA, Tsuyuki RT, Brilliant S. Primary health care teams: Perceptions of the collaborative process. Journal of Interprofessional Care. 2004; 18(1):75-78. PMid:14668104 http://dx.doi.org/10.1080/13561820410001639370

[36] Scott E, Cleary B. Professional polarities in nursing. Nursing Outlook. 2007; 55(5): 250-256. PMid:17950119 http://dx.doi.org/10.1016/j.outlook.2007.05.002

[37] Northam S. Conflict in the workplace, Part 2: Strategies to resolve conflict and restore collegial working relationships. American Journal of Nursing. 2009; 109(7):65-67. PMid:19546648 http://dx.doi.org/10.1097/01.NAJ.0000357176.86507.13

[38] Davis C. Keeping the peace: Conflict resolution training is paying immediate dividends for front line NHS staff, reports Carol Davis. Nursing Standard. 2007; 22(12):18-19. PMid:18087872

[39] Vestal K. Conflict and cooperation in the workplace. Nurse Leader. 2006; 4(6):6-7. http://dx.doi.org/10.1016/j.mnl.2006.09.008

[40] Mahon M, Nicotera A. Nursing and conflict communication: Avoidance as a preferred strategy. Nursing Administration Quarterly. 2011; 35(2):152-163. PMid:21403489 http://dx.doi.org/10.1097/NAQ.0b013e31820f47d5

[41] Westwood C. Managing difficult behavior. Nursing Management. 2010;17(6):20-21.

[42] Demshar J. Tips for navigating the hornet’s nest of conflicts in the workplace. Florida Nurse. 2010; 58(4):13. PMid:21329221

[43] Xyrichis A, Lowton K. What fosters or prevents interprofessional teamworking in primary and community care? A literature review. International Journal of Nursing Studies. 2008; 45(1):140-153. PMid:1738365 http://dx.doi.org/10.1016/j.ijnurstu.2007.01.015

[44] Cohen S. Recruitment and retention: How to get them and keep them. Nursing Mangement. 2013; 44(4): 11-14. PMid:23524556 http://dx.doi.org/10.1097/01.NUMA.0000428191.14389.ba

[45] Brinkert R. A literature review of conflict communication causes, costs, benefits and interventions in nursing. Journal of Nursing Management. 2010; 18(2):145-146. PMid:20465742 http://dx.doi.org/10.1111/j.1365-2834.2010.01061.x

[46] Schoonbeek S, Henderson A. Shifting workplace behavior to inspire learning: A journey to building a learning culture. Journal of Continuing Education in Nursing. 2011; 42(1):43-48. PMid:20954565 http://dx.doi.org/10.3928/00220124-20101001-02

[47] Siu H, Spence Laschinger H, Finegan J. Nursing professional practice environments: Setting the stage for constructive conflict resolution and work effectiveness. JONA. 2008; 38(5):250-257. PMid:18469619

http://dx.doi.org/10.1097/01.NNA.0000312772.04234.1f 